\title{
Evidence that Parathyroid Hormone-mediated Calcium Transport in Rat Brain Synaptosomes Is Independent of Cyclic Adenosine Monophosphate
}

Cosmo L. Fraser, Philip Sarnacki, and Amer Budayr

Divisions of Nephrology, Endocrinology, and Geriatrics, Department of Medicine, Veterans Administration Medical Center, San Francisco, California 94121; and University of California, San Francisco, California 94143

\begin{abstract}
In vivo PTH administration to rats resulted in increased brain synaptosomal $\mathrm{Ca}^{++}$transport, while parathyroidectomy (PTX) resulted in decreased transport. To determine the mechanism of action of PTH on $\mathrm{Ca}^{++}$transport in rat brain synaptosomes, we performed transport studies by the $\mathrm{Na}-\mathrm{Ca}$ exchanger and also measured cAMP generation in synaptosomes from PTX rats. $\mathrm{Ca}^{++}$transport was studied after in vivo additions of either bovine (b)PTH, cAMP, or forskolin, and adenylate cyclase activity was assessed after additions of either bPTH, forskolin, sodium fluoride (NaF), or isoproterenol. In the presence of 1-34 bPTH $\left[10^{-7} \mathrm{M}\right], \mathrm{Ca}^{++}$uptake was significantly increased by $55 \%(P<0.001)$ above control, while 3-34 bPTH $\left[10^{-7} \mathrm{M}\right]$ had no effect on uptake. Both $8 \mathrm{br}, \mathrm{cAMP}\left[10^{-6} \mathrm{M}\right]$ and dibut,cAMP $\left[10^{-6} \mathrm{M}\right]$ also significantly increased $(P$ $<0.001) \mathrm{Ca}^{++}$uptake above control by 63 and $44 \%$, respectively. Similarly, forskolin $\left[10^{-5} \mathrm{M}\right]$, the adenylate cyclase activator, increased $\mathrm{Ca}^{++}$uptake by $41 \%$. We next evaluated $\mathrm{Ca}^{++}$efflux, and found that 1-34 bPTH $\left[10^{-7} \mathrm{M}\right]$, 1-84 bPTH $\left[10^{-7} \mathrm{M}\right]$, and forskolin $\left[10^{-5} \mathrm{M}\right]$ also increased $\mathrm{Ca}^{++}$efflux by 50,73 , and $120 \%$, respectively, above control. Since $\mathrm{Ca}^{++}$ transport was increased by either PTH, cAMP, or forskolin, we decided to determine if PTH action on $\mathrm{Ca}^{++}$transport in synaptosomes was dependent on CAMP. This was investigated by measuring CAMP production during the conversion of ${ }^{32} \mathrm{P}$ ATP to ${ }^{32} \mathbf{P}$-cAMP in the presence of an ATP regenerating system (30 $\mu$ g creatine phosphokinase, $10 \mathrm{mM}$ creatine phosphate), and the cyclic nucleotide phosphodiesterase inhibitor (1 mM IBMX). Whereas forskolin $\left[10^{-4} \mathrm{M}\right]$ and NaF [100 $\mathrm{mM}$ ] significantly increased $(P<0.001)$ adenylate cyclase activity in synaptosomes by eight- and fourfold, respectively, neither 1-34 bPTH nor 1-84 bPTH increased synaptosomal cyclase activity. However, in canine renal cortical plasma membranes (CRCPM), we observed significant increases in CAMP production with either forskolin, NaF, or PTH. Finally, to determine if synaptosomes contain an intact adenylate cyclase system, we measured cAMP production in the presence of the beta adrenergic agent, isoproterenol. Isoproterenol signifi-
\end{abstract}

This paper was presented in part at the American Federation for Clinical Research, San Diego, CA, May 1987; and at the Tenth International Congress of Nephrology, London, England, July 1987.

Address correspondence and reprint requests to Dr. Cosmo L. Fraser, Division of Nephrology (111J), Veterans Administration Medical Center, 4150 Clement Street, San Francisco, CA 94121.

Received for publication 10 July 1987 and in revised form 5 October 1987.

The Journal of Clinical Investigation, Inc.

Volume 81, April 1988, 982-988 cantly increased adenylate cyclase activity in both synaptosomes (90\%) and CRCPM (50\%).

These data suggest that although there is an intact adenylate cyclase system in rat brain synaptosomes, PTH-stimulated calcium transport in synaptosomes appears to be independent of this system.

\section{Introduction}

Previously, we investigated the effects of uremia on calcium transport in synaptosomes that were isolated from rat brain and found that both the $\mathrm{Na}-\mathrm{Ca}$ exchanger and the ATP-dependent calcium pump were altered by uremia (1). The nature of the alteration was such that calcium accumulation was increased in the uremic vesicles by both these transport mechanisms. We further observed that when parathyroidectomy was performed in rats before they were made acutely uremic, the transport alterations in uremia were no longer seen (2). Additionally, the administration of PTH to parathyroidectomized rats that were then made uremic, resulted in a return of the calcium transport abnormalities. The magnitude of the alteration in this group of rats was similar to that which was observed in the nonparathyroidectomized uremic group. In nonuremic rats, the absence or presence of PTH also affected calcium transport in a manner similar to that which we observed in uremia: parathyroidectomy and PTH administration decreased and increased calcium transport, respectively (3). Based on these observations we decided to investigate the mechanism of action of PTH on calcium transport in rat brain synaptosomes to determine if its action was cAMP-mediated, as has been classically described in tissues such as bone (4) and kidney (5-7).

\section{Methods}

\section{Isolation of synaptosomes}

Synaptosomes were isolated from 200-g male Sprague-Dawley rats as we previously described (8). In brief, the rats were decapitated and their cerebral cortex removed and immediately placed in $10 \mathrm{ml}$ of ice-cold isolation media containing $320 \mathrm{mM}$ sucrose, $0.2 \mathrm{mM} \mathrm{K}$-EDTA, $5 \mathrm{mM}$ Tris- $\mathrm{HCl}\left(\mathrm{pH} \mathrm{7.4)}\right.$ at $0-4^{\circ} \mathrm{C}$. The brains were chopped finely with scissors, washed with the isolation media, and homogenized in a glass Dounce homogenizer (clearance $1 \mathrm{~mm}$ ). The crude synaptosomal-mitochondrial pellet was obtained after several centrifugations at $1,300 \mathrm{~g}$ for $3 \mathrm{~min}$ and a final spin at $18,000 \mathrm{~g}$ for $10 \mathrm{~min}$. The purified synaptosomal preparation was then obtained by differential centrifugation on a discontinuous Ficoll gradient for $60 \mathrm{~min}(8)$. The synaptosomal protein was diluted in isolation media to a final concentration of 8-10 $\mathrm{mg} / \mathrm{ml}$ and used for transport studies.

\section{Calcium transport assay}

Uptake studies. Calcium uptake studies were carried out by the $\mathrm{Na}-\mathrm{Ca}$ exchange mechanism as previously described (1). An $0.5-\mathrm{ml}$ aliquot of 
synaptosomal protein ( $~ 5 \mathrm{mg}$ protein) was brought up to $2 \mathrm{ml}$ in a preequilibration media $\left(140 \mathrm{mM} \mathrm{NaCl}, 1 \mathrm{mM} \mathrm{MgSO}_{4}, 10 \mathrm{mM}\right.$ glucose, $5 \mathrm{mM}$ Hepes-Tris, $\mathrm{pH}$ 7.4) and allowed to incubate for $10 \mathrm{~min}$ at $37^{\circ} \mathrm{C}$. The suspension was then spun at $20,000 \mathrm{~g}$ for $5 \mathrm{~min}$ and the resulting pellet was resuspended in the same media and spun at the same speed for $5 \mathrm{~min}$. At the end of the second spin, the final pellet was resuspended in $400 \mu \mathrm{l}$ of the preequilibration media and kept on ice $\left(0-4^{\circ} \mathrm{C}\right)$ until transport studies were commenced.

Uptake was initiated by adding $5 \mu$ l of synaptosomal suspension ( $\sim 50 \mu$ g protein) to $95 \mu \mathrm{l}$ of an external media consisting of $140 \mathrm{mM}$ $\mathrm{KCl}, 1 \mathrm{mM} \mathrm{MgSO} 4,10 \mathrm{mM}$ glucose, $10 \mu \mathrm{M} \mathrm{CaCl}_{2}, 0.1 \mu \mathrm{Ci}^{45} \mathrm{Ca}^{++}$ $(40,000 \mathrm{cpm} / 20 \mu \mathrm{l}), 5 \mathrm{mM}$ Hepes-Tris, $\mathrm{pH} 7.4$ at $25^{\circ} \mathrm{C}$. Depending on the compound being studied, either $100 \mathrm{ng} / \mathrm{ml}$ bovine parathyroid extract, $10^{-7} \mathrm{M}$ 1-34 bPTH, $10^{-7}$ M 1-84 bPTH, $10^{-6}$ M 8bromocAMP, $10^{-6} \mathrm{M}$ dibut-cAMP, or $10^{-5} \mathrm{M}$ forskolin was added to the external media before transport study was begun. After the desired period of incubation, uptake was terminated by adding to the uptake media $2 \mathrm{ml}$ of ice-cold $150 \mathrm{mM} \mathrm{KCl}$ solution (stop solution). The mixture was immediately vacuum filtered through a $0.45-\mu \mathrm{m}$ pore size cellulose acetate filter and washed twice with $2 \mathrm{ml}$ of the cold stop solution as previously described (1). The filters were dissolved in phase combine scintillant and counted by a Packard counter (model 2000CA; Packard Instrument Co., Inc., Downers Grove, IL). Each time point was done in triplicate and the value obtained at time zero, which we attributed to binding of calcium to protein and filter, was subtracted from each of the points of observation $(1,8)$. As we described previously, nonspecific binding to the filter and synaptosomal protein was $<0.05 \%$ (1).

Efflux studies. For calcium efflux studies the vesicles are loaded by the $\mathrm{Na}-\mathrm{Ca}$ exchanger for $10 \mathrm{~min}$ as discussed above. At the end of this period, the loaded vesicles are spun at $20,000 \mathrm{~g}$ for $10 \mathrm{~min}$ and resuspended to a protein concentration of $10 \mathrm{mg} / \mathrm{ml}$ in the external media

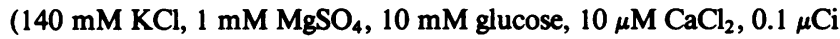
${ }^{45} \mathrm{Ca}^{++} 40,000 \mathrm{cpm} / 20 \mu \mathrm{l}, 5 \mathrm{mM}$ Hepes-Tris, $\mathrm{pH} 7.4$ ) and kept on ice until efflux studies were commenced. Efflux was promptly started by diluting $5 \mu \mathrm{l}$ of the calcium-loaded vesicles in $95 \mu \mathrm{l}$ of a calcium-free efflux media consisting of $140 \mathrm{mM} \mathrm{NaCl}, 1 \mathrm{mM} \mathrm{MgSO}, 10 \mathrm{mM}$ glucose, $5 \mathrm{mM}$ Hepes-Tris, $\mathrm{pH} 7.4$ at $25^{\circ} \mathrm{C}$ with appropriate additions of either $10^{-7} \mathrm{M}$ 1-34 bPTH, $10^{-7} \mathrm{M}$ 1-84 bPTH, $10^{-6} \mathrm{M}$ 8bromocAMP, $10^{-6} \mathrm{M}$ dibut-cAMP, or $10^{-5} \mathrm{M}$ forskolin. At the appropriate period of efflux the reaction was terminated by adding $2 \mathrm{ml}$ of ice-cold stop solution to $100 \mu \mathrm{l}$ of the transport mixture (9). The mixture was then filtered as above, washed twice with the stop solution, and counted. The initial time point was obtained at the instant before starting the efflux studies and taken as the maximum value of calcium where comparison was made over time.

\section{Purification of canine renal cortical plasma membranes}

Highly purified renal cortical plasma membranes were isolated from freshly removed canine kidney at $0-4^{\circ} \mathrm{C}$. Cortical tissue was dissected free from medullary tissues, cut into small pieces with scissors, and washed in $0.9 \% \mathrm{NaCl}, 1 \mathrm{mM}$ EDTA, $5 \mathrm{mM}$ Tris- $\mathrm{HCl}$, pH 7.5. The medium was decanted and the tissue was disrupted in 3 vol (relative to wet weight) ice-cold $0.25 \mathrm{M}$ sucrose, $1 \mathrm{mM}$ EDTA, $5 \mathrm{mM}$ Tris-HCl, pH 7.5 (SET buffer), ${ }^{1}$ using two to three short bursts $(<5 \mathrm{~s})$ of a Polytron homogenizer (Brinkmann Instruments, Westbury, NY). Tissue was further homogenized using 10 strokes of a motor-driven loose Teflon pestle. After centrifugation at $1,475 \mathrm{~g}$ for $10 \mathrm{~min}$, the pellets were washed once with SET buffer then resuspended in 1 vol (relative to initial wet weight) $2 \mathrm{M}$ sucrose, $1 \mathrm{mM}$ EDTA, and $5 \mathrm{mM}$ Tris- $\mathrm{HCl}$, pH 7.5. The suspension was spun at $13,300 \mathrm{~g}$ for $10 \mathrm{~min}$ and the supernatant was decanted and diluted eightfold with $1 \mathrm{mM}$ EDTA, 5

1. Abbreviations used in this paper: CRCPM, canine renal cortical plasma membrane; DAG, diacylglycerol; IP3, inositol trisphosphate; IP4, inositol 1,3,4,5-tetrakisphosphate; SET buffer, $0.25 \mathrm{M}$ sucrose, 1 mM EDTA, 5 mM Tris- $\mathrm{HCl}$, pH 7.5.
$\mathrm{mM}$ Tris- $\mathrm{HCl}, \mathrm{pH}$ 7.5. This suspension was centrifuged at $20,000 \mathrm{~g}$ for $15 \mathrm{~min}$ and the white upper layer of the pellet was gently removed, resuspended in SET buffer, and respun. This process of centrifugation and resuspension was repeated three times to yield a homogeneous white fluffy pellet (10).

\section{Guanyl nucleotide-amplified adenylate cyclase assay}

Adenylate cyclase activity was measured by the conversion of [alpha$\left.{ }^{32} \mathrm{P}\right]$ ATP to [ ${ }^{32} \mathrm{P}$ ]cAMP. Standard incubations were carried out in a final volume of $0.1 \mathrm{ml}$ containing $25 \mathrm{mM}$ Tris- $\mathrm{HCl}, \mathrm{pH} 7.5,2 \mathrm{mM}$ $\mathrm{MgCl}_{2}, 0.1 \%$ BSA, $0.1 \mathrm{mM}$ [alpha- ${ }^{32}$ P]ATP (100-300 cpm/pmol), an ATP regenerating system consisting of $30 \mu \mathrm{g}$ creatine phosphokinase and $10 \mathrm{mM}$ creatine phosphate, and $1 \mathrm{mM} 1$-methyl,3-isobutylxantine, a potent inhibitor of cyclic nucleotide phosphodiesterase (11). GTP at final concentrations of $100 \mu \mathrm{M}$ was sometimes added to augment the sensitivity of adenylate cyclase to PTH (10). Appropriate concentrations of either 1-34 bPTH, 1-84 bPTH, forskolin, NaF, or isoproterenol were also added depending on experimental protocol. Incubation tubes were made of borosilicate glass and were pretreated with dichlorodimethylsilane (Aldrich Chemical Co., Inc., Milwaukee, WI) to reduce adsorption of PTH. Incubations were started by adding either canine renal cortical plasma membranes (CRCPM) or synaptosomes in SET buffer or buffer alone for assay blank. After $30 \mathrm{~min}$ of incubation at $30^{\circ} \mathrm{C}$, enzyme activity was terminated by the addition of $0.1 \mathrm{ml}$ of a solution containing $10 \mathrm{mM}$ unlabeled ATP, $2 \%$ SDS (vol/ vol), $50 \mathrm{mM}$ Tris- $\mathrm{HCl}$ at $\mathrm{pH} 7.5,1 \mathrm{mM}\left[{ }^{3} \mathrm{H}\right] \mathrm{cAMP}(30,000 \mathrm{cpm})$. Assay tubes were immediately placed in a boiling water bath for $3 \mathrm{~min}$ and $\left.{ }^{32} \mathrm{P}\right]$ cAMP was isolated by chromatographic procedure $(10,12)$. For studies with hypotonically lysed synaptosomal vesicles, lysis was achieved with $20 \mathrm{mM}$ Tris- $\mathrm{HCl}$ as previously described (9).

\section{Protein assay}

Protein determination on the membrane preparations were determined by the methods of Lowry and associates using BSA as the reference standard (13).

\section{Materials}

Highly purified bovine PTH tetratriacontapeptide [1-34 bPTH, 1-84 bPTH, 3-34 bPTH], [alpha- $\left.{ }^{32} \mathrm{P}\right] \mathrm{ATP},\left[{ }^{3} \mathrm{H}\right] \mathrm{cAMP}$, and Gpp(NH)p were all generous gifts from Dr. Claude Arnaud (Endocrine Division, VA Medical Center, San Francisco, CA). ATP, cAMP, forskolin, 1methyl,3-isobutylxantine, creatine phosphate, creatine phosphokinase, forskolin, and sodium fluoride were obtained from Sigma Chemical Co. (St. Louis, MO). ${ }^{45} \mathrm{Ca}^{++}$was obtained from New England Nuclear (Boston, MA). All other chemicals were of reagent grade and obtained from Sigma Chemical Co.

\section{Results}

We first performed calcium uptake by the $\mathrm{Na}-\mathrm{Ca}$ exchanger in synaptosomes as described in Methods and observations were made between 3 and $60 \mathrm{~s}$. As shown in Fig. 1, with either 100 $\mathrm{ng} / \mathrm{ml}$ of parathyroid extract or $10^{-7} \mathrm{M} 1-34 \mathrm{bPTH}$, uptake was significantly increased $(P<0.001)$ from $0.31 \pm 0.01$ to $0.44 \pm 0.01$ and $0.48 \pm 0.01 \mathrm{nmol} / \mathrm{mg}$ protein, respectively, at 5 s. This PTH stimulation resulted in an increase in uptake of $42 \%$ with the extract and $55 \%$ with 1-34 bPTH. In the presence of PTH, uptake was significantly increased only up to $15 \mathrm{~s}$; thereafter no difference was observed between PTH and the control group (Fig. 1). This suggests that the ability of PTH to stimulate calcium uptake in synaptosomes is transient and may be related to a finite amount of available substrate (ATP) within the vesicles. However, as we previously described, synaptosomes contain $\sim 0.35 \mathrm{mM}$ ATP, which is adequate to drive the system for more than $15 \mathrm{~s}$, as will be shown later (8). 


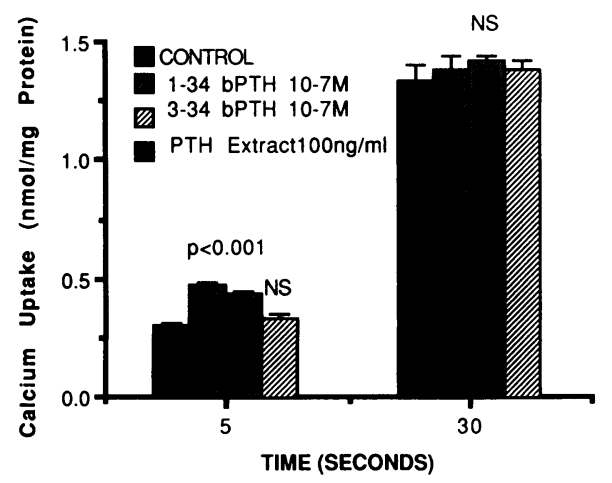

Figure 1. This graph shows the effects of three different PTH molecules on calcium uptake in synaptosomes. Uptake in the presence of either $100 \mathrm{ng} / \mathrm{ml}$ of parathyroid extract or $10^{-7}$ M 1-34 bPTH significantly increased calcium uptake above control at $5 \mathrm{~s}(P<0.001)$. $10^{-7}$ M 3-34 bPTH had no stimulatory effects on uptake. At $30 \mathrm{~s}$ uptake of all three groups was not different from control. Data are expressed as mean $\pm \mathrm{SE}$ of eight experiments.

As opposed to 1-34 bPTH and the extract, 3-34 bPTH did not change calcium uptake from control values during the period of observation. To determine if calcium uptake in synaptosomes was stimulated by cAMP as was observed with PTH, we next performed uptake studies in the presence of $10^{-6} \mathrm{M}$ of either 8,bromo-cAMP or dibut-cAMP for up to $5 \mathrm{~min}$ (Fig. 2). Between 3 and $30 \mathrm{~s}$, both cAMP molecules significantly increased $(P<0.005)$ calcium uptake in a manner that was similar to PTH. At 5 s 8,bromo-cAMP significantly increased uptake by $63 \%$ from $0.32 \pm 0.02$ to $0.52 \pm 0.03 \mathrm{nmol} / \mathrm{mg}$ protein, and dibuteryl-cAMP increased uptake by $44 \%$ above control. However, by $5 \mathrm{~min}$, calcium uptake was no longer stimulated by cAMP and the values in all three groups were not significantly different from each other (Fig. 2). Based on these data, it appears that PTH may stimulate calcium transport in synaptosomes by a cAMP-mediated action. Thus, to investigate this possibility we first decided to study the action of forskolin on calcium transport, in order to determine if direct stimulation of the adenylate cyclase catalytic subunit by

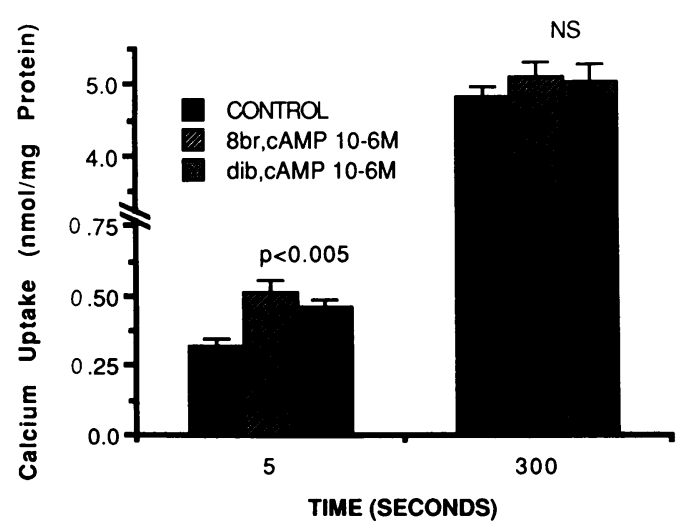

Figure 2. This graph shows the effects of 8,bromo-cAMP and dibutcAMP on calcium uptake. In the presence of cAMP, uptake is significantly greater than in control vesicles at $5 \mathrm{~s}$. No difference in uptake was observed between the groups at $5 \mathrm{~min}$, by which time maximum uptake was achieved. Data are expressed as the mean \pm SE of 10 experiments.

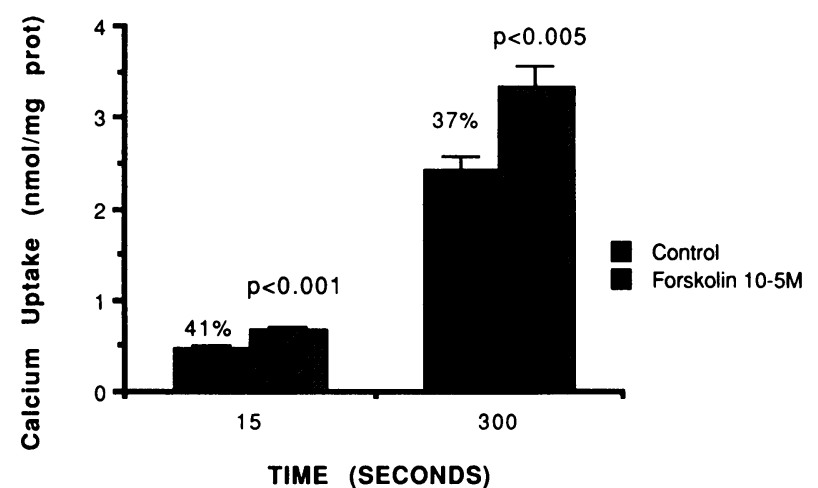

Figure $3.10^{-5} \mathrm{M}$ forskolin, activator of the catalytic subunit of adenylate cyclase, increased calcium uptake by 41 and $37 \%$ at $15 \mathrm{~s}$ and 5 min, respectively. Data are expressed as the mean \pm SE of nine experiments.

forskolin (14) would increase synaptosomal calcium transport, as was observed with PTH.

Calcium uptake was assessed by adding $10^{-5} \mathrm{M}$ forskolin to the external media and following transport over time ( $3 \mathrm{~s}$ to 10 $\mathrm{min}$ ). Throughout the period of observation (Fig. 3), calcium uptake in the presence of forskolin was significantly increased $(P<0.005)$ above control by $\sim 40 \%$. This prolonged stimulation of calcium uptake by forskolin was distinctly different from the transient increases observed with either PTH or cAMP. Since forskolin activates the cyclase system by binding to the catalytic subunit, it is evident that the native intrasynaptosomal ATP is sufficient to produce a sustained uptake by PTH.

We next decided to determine if calcium efflux from synaptosomes was also affected by PTH. As shown in Fig. 4, efflux in the presence of $10^{-7} \mathrm{M} 1-34 \mathrm{bPTH}$ was significantly increased $(P<0.005)$ above control by $29-50 \%$ between 3 and $10 \mathrm{~s}$. Similarly, $10^{-7} \mathrm{M} 1-84 \mathrm{bPTH}$ also significantly increased calcium efflux above control by $32-73 \%$ at the same time interval. With $10^{-5} \mathrm{M}$ forskolin, efflux was increased above control by $42-120 \%$, again suggesting the possible dependence of PTH stimulation of calcium transport on cAMP. To ensure that these differences in calcium transport were due to active

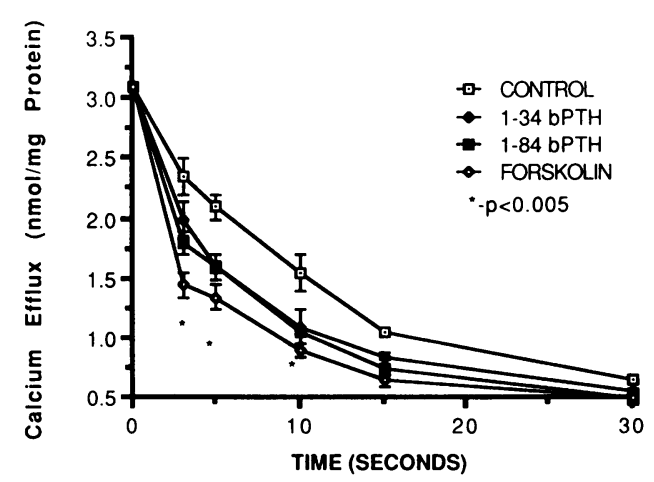

Figure 4. This graph shows calcium efflux from synaptosomes in the presence of $10^{-7} \mathrm{M}$ of either 1-34 bPTH or 1-84 bPTH. In the presence of PTH calcium efflux is significantly greater $(P<0.005)$ than in control vesicles between 3 and $10 \mathrm{~s}$. Data are expressed as mean \pm SE of eight experiments. 

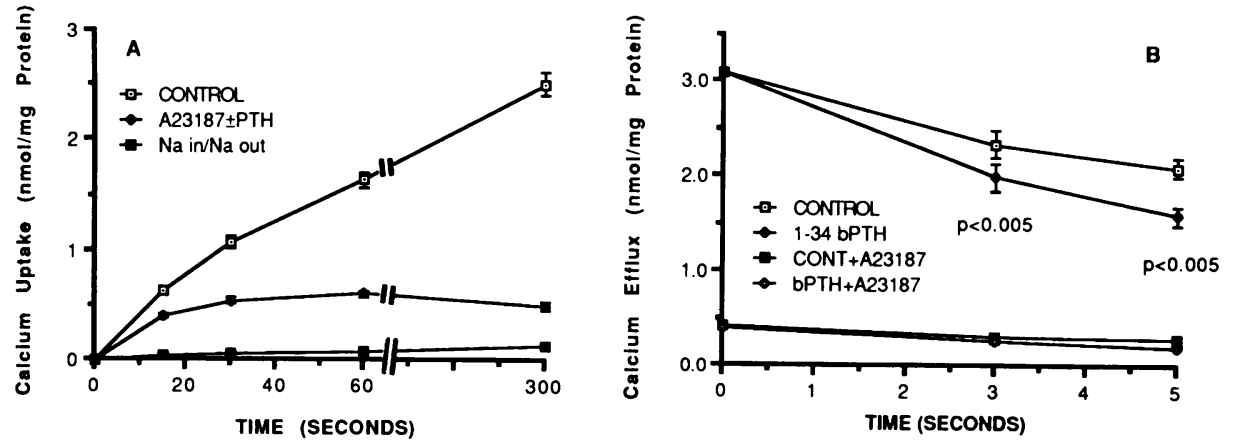

Figure 5. The graph in $A$ shows the effect of the calcium ionophore A23187 and the absence of a sodium gradient ( $\mathrm{Na} \mathrm{in/Na} \mathrm{out)} \mathrm{on} \mathrm{calcium} \mathrm{uptake} \mathrm{in}$ synaptosomes. In the absence of a gradient, calcium uptake was only $\sim 5 \%$ of control values. A23187 also prevented the vesicles from actively taking up calcium. In $B, A 23187$ preincubated in loading media prevented the vesicles uptaking calcium and thus equilibrated calcium concentration inside and outside of the vesicles. In the absence of A23187 significant difference in efflux was observed between control and PTH-treated vesicles. Data are expressed as mean $\pm \mathrm{SE}$ of eight experiments. uptake and efflux of calcium by the sodium/calcium exchanger and not nonspecific binding, we simultaneously performed transport studies in the presence of the calcium ionophore A23187, and also measured uptake in the absence of a sodium gradient (Fig. 5). As demonstrated in Fig. $5 \mathrm{~A}$, in the absence of a sodium gradient ( $\mathrm{Na}$ in/ $\mathrm{Na}$ out), no significant uptake was observed over $5 \mathrm{~min}$ of observation. Similarly, the ionophore A23187 equilibrated the calcium concentration between the inside and outside of the vesicles, thus preventing the active uptake that is observed in the presence of a sodium gradient and the absence of the ionophore (Fig. $5 \mathrm{~A}$ ). In efflux studies, A23187 also eliminated the observed differences in transport between control vesicles and those treated with PTH (Fig. $5 \mathrm{~B}$ ). Both these studies and the subtraction of time zero counts from ensuing points (see Methods) suggest that nonspecific binding of calcium to synaptosomes does not influence the results of these studies. These observations are similar to our previously published findings (1). In considering the entire data thus far, we felt that the preponderance of the evidence suggested that PTH-dependent calcium transport in synaptosomes was dependent on cAMP. To determine if this was the case, we then measured cAMP production rates in synaptosomes in the presence of either PTH or the membrane adenylate cyclase activators forskolin and sodium fluoride $(\mathrm{NaF})$. These three compounds were used in order to systematically analyze the three distinct subunits of the hormone-responsive adenylate cyclase system that are responsible for the generation of cAMP (14).

As explained in Methods, cAMP production was evaluated during the conversion of [alpha- $\left.{ }^{32} \mathrm{P}\right] \mathrm{ATP}$ to [alpha- $\left.{ }^{32} \mathrm{P}\right] \mathrm{cAMP}$ in the presence of both an ATP regenerating system and an inhibitor of cyclic nucleotide phosphodiesterase. The purpose of these additions was to provide enough substrate to maintain adequate ATP concentration during the production of CAMP, and also to prevent the breakdown of cAMP once it was formed. Studies were performed simultaneously in CRCPM and in synaptosomes. The CRCPMs were used as control for the studies in synaptosomes. Table I shows that the addition of either 30,300 , or $100,000 \mathrm{ng} / \mathrm{ml}$ of $1-34 \mathrm{bPTH}$ resulted in $\sim 3-, 4.5-$, and 5-fold increase in adenylate cyclase activity in CRCPM, respectively. At the same time no increase in cyclase activity was observed in synaptosomes with the same concentrations of $1-34$ bPTH. Similarly, with either 10 or $500 \mathrm{ng} / \mathrm{ml}$ of 1-84 bPTH, adenylate cyclase activity increased from $250 \pm 15$ to $519 \pm 22$ or to $1,036 \pm 45 \mathrm{pmol} \mathrm{cAMP} / \mathrm{mg}$ protein in CRCPM, an increase of two- and fourfold, respectively. In synaptosomes, cyclase activity was also unaffected by $1-84$ bPTH $(1,300 \pm 98$ to $1,357 \pm 34$ or $1,290 \pm 75 \mathrm{pmol} \mathrm{cAMP} / \mathrm{mg}$ protein). To determine if either the catalytic or the guanine nucleotide regulatory subunits were operative in synaptosomes, we then carried out experiments in the presence of 0.1 $\mathrm{mM}$ forskolin, activator of the catalytic subunit of the adenylate cyclase system (14). In CRCPM (Table I), adenylate cyclase activity increased from $239 \pm 34$ to $3,330 \pm 145 \mathrm{pmol}$ cAMP $/ \mathrm{mg}$ protein, and in synaptosomes from $911 \pm 51$ to $7,466 \pm 420$ pmol cAMP/mg protein. Similarly, $100 \mathrm{mM} \mathrm{NaF}$ (activates adenylate cyclase through the stimulatory guanine nucleotide regulatory subunit) increased cyclase activity from $239 \pm 34$ to $6,669 \pm 310$ in CRCPM and from $911 \pm 51$ to $3,562 \pm 248$ in synaptosomes. These results suggest that both the catalytic and regulatory subunits of the adenylate cyclase system are intact

Table I. Adenylate Cyclase Activity Measured as a Function of Increasing Concentration of Known Cyclase Activators

\begin{tabular}{lccc}
\hline & & \multicolumn{2}{c}{ Adenylate cyclase activity } \\
\cline { 3 - 4 } \multicolumn{1}{c}{ Agents } & Concentration & CRCPM & Synaptosomes \\
\hline & & pmol cAMP/mg prot. 30 min \\
No. of experiments & & 5 & 5 \\
$1-34$ bPTH $(n g / m l)$ & 0 & $278 \pm 11$ & $911 \pm 51$ \\
& 30 & $763 \pm 25(2.7)$ & - \\
& 300 & $1,230 \pm 36(4.4)$ & $953 \pm 57$ \\
$1-84$ bPTH $(n g / m l)$ & 100,000 & $1,411 \pm 40(5.1)$ & $922 \pm 44$ \\
& 0 & $250 \pm 15$ & $1,300 \pm 98$ \\
Forskolin $(m M)$ & 10 & $519 \pm 22(2.1)$ & $1,357 \pm 34$ \\
& 500 & $1,036 \pm 45(4.1)$ & $1,290 \pm 75$ \\
NaF $(m M)$ & 0 & $239 \pm 34$ & $911 \pm 51$ \\
& 0.1 & $3,330 \pm 145(14)$ & $7,466 \pm 420(8.2)$ \\
& 0 & $239 \pm 34$ & $911 \pm 51$ \\
& 100 & $6,669 \pm 310(28)$ & $3,562 \pm 248(4)$
\end{tabular}

Activity was measured in the presence of $1 \mathrm{mM}$ IBMX, $10 \mathrm{mM}$ creatine phosphate and $30 \mu \mathrm{g}$ creatine phosphokinase. Parentheses indicate the fold increase in cyclase activity above control. Data are expressed as mean $\pm \mathrm{SE}$; each time point was done in triplicate. 
and functional in synaptosomes, and that the mechanism of action of PTH on calcium transport in synaptosomes may be independent of cAMP.

To determine if the tightness of the synaptosomal membrane prevented the externally added ${ }^{32} \mathrm{P}$-ATP from entering the vesicle, resulting in the labeled ATP being unavailable for conversion to ${ }^{32} \mathrm{P}$-cAMP, we next measured cAMP production in both intact and lysed synaptosomes (Fig. 6). No difference in cAMP production was observed between the intact and the hypotonically lysed synaptosomes. Thus, it does not appear that the inability of synaptosomes to produce cAMP by PTH is due to the unavailability of the added ATP. In experiments that were simultaneously performed in CRCPM, increasing concentration of PTH resulted in increased cAMP production (Fig. 6).

To investigate if PTH effect on calcium transport was independent of cAMP, it was necessary for us to determine if an intact adenylate cyclase system exists in synaptosomes. To achieve this, we evaluated adenylate cyclase activity in synaptosomes in the presence of isoproterenol, a beta adrenergic agonist that is a well-known adenylate cyclase activator (14). Table II shows that $10 \mathrm{mM}$ isoproterenol resulted in $90 \%$ increase in cyclase activity in synaptosomes and $50 \%$ increase in CRCPM, and suggests that there is an intact adenylate cyclase system in synaptosomes that is at least active as in CRCPM. Therefore, the inability of PTH to stimulate cAMP production in synaptosomes does not appear to be due to the absence of an intact adenylate cyclase system, but to an inability of PTH to activate the cyclase system in synaptosomes.

\section{Discussion}

In the studies described above, it is shown that PTH increases both the uptake and the efflux of calcium from rat brain synaptosomes in a manner similar to either cAMP or forskolin. Based on these findings, it was initially felt that the mechanism

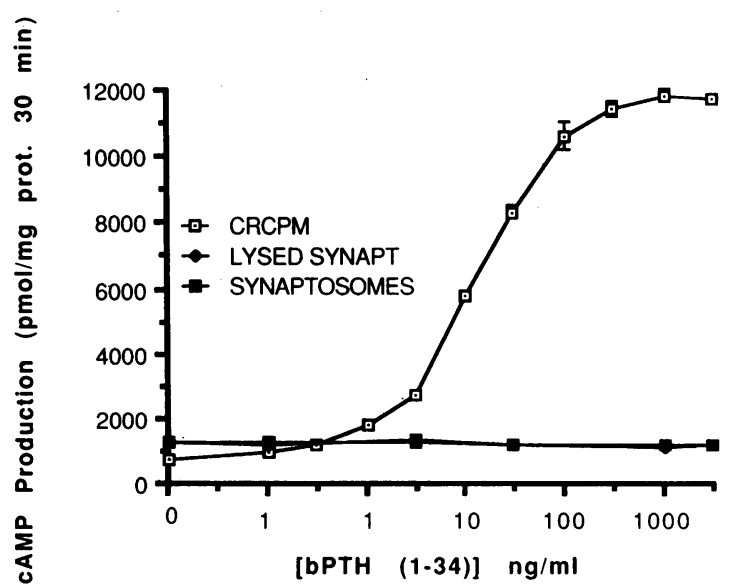

Figure 6. This graph shows the effects of PTH on adenylate cyclase activity in CRCPM, intact synaptosomes, and lysed synaptosomal plasma membranes (LYSED SYNAPT). In CRCPM increased concentration of 1-34 PTH results in increased production of cAMP, however, CAMP production was not increased in either of the synaptosomal preparations. The experiment was carried out in the presence of GTP, IBMX, creatine phosphate, and creatine phosphokinase. Data are expressed as mean $\pm \mathrm{SE}$.
Table II. Ability of 1-34 bPTH and the Beta Adrenergic Agonist Isoproterenol to Activate Adenylate Cyclase Activity in Synaptosomes and CRCPM

\begin{tabular}{|c|c|c|c|}
\hline \multirow[b]{2}{*}{ Agents } & \multirow[b]{2}{*}{ Concentration } & \multicolumn{2}{|c|}{ Adenylate cyclase activity } \\
\hline & & CRCPM & Synaptosomes \\
\hline & & \multicolumn{2}{|c|}{ pmol cAMP $/ \mathrm{mg}$ prot. $30 \mathrm{~min}$} \\
\hline $1-34$ bPTH $(n g / m l)$ & $\begin{array}{r}0 \\
30 \\
1,000\end{array}$ & $\begin{array}{c}242 \pm 8 \\
3,357 \pm 41(14) \\
4,363 \pm 57(18)\end{array}$ & $\begin{array}{l}1,080 \pm 41 \\
1,198 \pm 37 \\
1,148 \pm 16\end{array}$ \\
\hline Isoproterenol $(\mu M)$ & $\begin{array}{r}0 \\
100 \\
10,000\end{array}$ & $\begin{array}{l}253 \pm 14 \\
390 \pm 21(1.5) \\
367 \pm 7(1.5)\end{array}$ & $\begin{array}{l}1,116 \pm 21 \\
1,307 \pm 7(1.2) \\
2,099 \pm 114(1.9)\end{array}$ \\
\hline
\end{tabular}

Activity was measured in the presence of GTP, $1 \mathrm{mM}$ IBMX, $10 \mathrm{mM}$ creatine phosphate, and $30 \mu \mathrm{g}$ creatine phosphokinase. Parentheses indicate the fold increase in cyclase activity due to the agents. Data are expressed as mean $\pm \mathrm{SE}$.

of action of PTH on calcium transport in synaptosomes was cAMP dependent. It was also observed that parathyroid extract and 1-34 bPTH increased synaptosomal calcium transport, while 3-34 bPTH had no such effect on uptake (Fig. 1). This suggested to us that the amino acids in positions 1 and 2 of the PTH molecule are necessary for PTH to stimulate calcium transport in synaptosomes. As a result of these observations, we used 1-34 bPTH and 1-84 bPTH in all subsequent studies, and the results indicate that both PTH molecules produced similar responses in calcium transport and cAMP generation in synaptosomes.

As mentioned above, our initial observations that PTH stimulated calcium transport in synaptosomes was similar to that observed with cAMP and forskolin (Figs. 1-4) lead us to believe that this mechanism of action of PTH was CAMP dependent. However, the inability of PTH to generate cAMP in synaptosomes suggested to us that the relationship between PTH and synaptosomal calcium transport was more complicated than we initially thought. This complexity became more intriguing when PTH increased cyclase activity in CRCPM by fivefold in simultaneously run experiments (Table I). Our aim, then, was to determine if there was an intact adenylate cyclase system in synaptosomes, and whether its function could be demonstrated by other known activators of the adenylate cyclase system. Our first task was to measure cAMP production in synaptosomes and CRCPM in the presence of either forskolin or $\mathrm{NaF}$ and to compare the results in these two membrane preparations. In both preparations, forskolin as well as $\mathrm{NaF}$ increased cyclase activity many fold (Table I), suggesting that synaptosomes contain both a catalytic and the guanine nucleotide regulatory subunits that are similar to that in CRCPM.

We next measured cAMP production in both membrane preparations in the presence of isoproterenol, a beta adrenergic agonist, which produces many of its functions by first binding to surface receptors, causing an increase in cAMP production and activation of a cAMP-dependent protein kinase (15). As shown previously (Table II), 1-34 bPTH increased adenylate cyclase activity 18-fold in CRCPM, while it had no effect on the cyclase activity in synaptosomes. However, with isoproterenol, cyclase activity was increased by $50 \%$ in CRCPM and 90\% in synaptosomes. This suggested that like CRCPM, synaptosomes contain an intact adenylate cyclase system that can 
be stimulated by cyclase activators other than PTH. Thus, it appears that the PTH-stimulated calcium transport observed in synaptosomes is independent of cAMP.

Under other conditions where a hormone-responsive adenylate cyclase system exists, the role of the hormone in eliciting cAMP responses can be demonstrated by measuring cAMP production in the presence of the hormone $(14,16)$. Examples of this relationship include: inhibition of platelet aggregation by prostaglandins (17), stimulation of lipolysis in adipocytes, stimulation of steroidogenesis in rat adrenal cells, relaxation of peripheral smooth muscle, and enhancement of secretion from blowfly salivary glands (14). However, in our studies (Table I), both 1-34 and 1-84 bPTH failed to produce cAMP in synaptosomes, despite the presence of an intact adenylate cyclase system (Table II). This again suggests that PTH action on calcium transport in brain synaptosomes may not require the presence of cAMP.

As with our observations in synaptosomes, studies in other tissues have shown that PTH can produce cellular changes that are independent of the adenylate cyclase system. In a recent study it was shown by Hruska and associates that PTH increased intracellular calcium in proximal tubular cells of the mammalian kidney independently of the cyclic nucleotides (18). Similarly, in the opossum kidney cell line, which exhibits proximal tubular characteristics, it was also shown that PTH increased cytoplasmic calcium and produced a dose-dependent stimulation of inositol triphosphate (IP3) and diacylglycerol (DAG) which was not mimicked by cAMP (19). In the isolated papillary muscle from rat heart, PTH action on papillary muscle contraction was also shown to be independent of cAMP (20). In this study it was shown that the inotropic action of PTH on papillary muscle was mediated by the release of endogenous norepinephrine from the myocardium, and that both the release of norepinephrine and muscle contraction were independent of adenylate cyclase activation (20). Thus, it is evident from these studies that the mechanism of action of PTH on cellular functions is quite variable and does not necessarily involve the adenylate cyclase system. The data from our studies support these findings and our contention that PTH action on calcium transport in rat brain synaptosomes may be independent of cAMP.

A recent study has shown that inositol 1,3,4,5-tetrakisphosphate (IP4) activates sea urchin eggs by a mechanism that was dependent on external calcium (21). Similarly, hepatocytes whose functions are coupled to the inositides stimulated by an agonist such as vasopressin, produced a prolonged increase in intracellular calcium concentration that is dependent on extracellular calcium (22). IP4 has been shown to rise rapidly in rat cerebral cortical slices after muscarinic receptor stimulation (23), and to decline just as rapidly by inhibition of the receptor $(23,24)$. Thus, it appears that after the agonist binds to surface receptors, phosphoinositol, a membranebound lipid, is converted to DAG and IP3, which is then phosphorelated to IP4. IP4 by itself and/or with IP3 or DAG changes the membrane permeability of the cell to calcium so that there is an influx of calcium from the extracellular space to the cytosol (21). The increased intracellular calcium that is produced as a result of this mechanism is different from that which is observed after the release of microsomal calcium by IP3 in tissues such as liver, muscle, bag cell neurons, and kidney $(19,25,26)$. This regulation of intracellular calcium from extracellular sources by an agonist is an important one and might be a possible mechanism of action of PTH in synaptosomes.

\section{Acknowledgments}

The authors would like to thank Dr. Allen I. Arieff for his strong support of this project; Drs. Claude Arnaud and Robert Nissenson of the Endocrine Division for their advice and helpful discussions; and Dr. Robert Klein, also of the Endocrine Division, for performing some of the adenylate cyclase assays.

This research is supported in part by the Research Services of the Veterans Administration Medical Center, San Francisco, California. Dr. Fraser is a Research Associate of the Veterans Administration.

\section{References}

1. Fraser, C. L., P. Sarnacki, and A. I. Arieff. 1985. Calcium transport abnormality in uremic rat brain synaptosomes. J. Clin. Invest. 76:1789-1795.

2. Fraser, C. L., and A. I. Arieff. 1986. Abnormalities of transport in synaptosomes from uremic rat brain: role of parathyroid hormone. J. Gen. Physiol. 88:24. (Abstr.)

3. Fraser, C. L., and P. Sarnacki. 1988. Parathyroid hormone mediates changes in calcium transport in uremic rat brain synaptosomes. Am. J. Physiol. 23:6.

4. Chase, L. R., S. A. Fedack, and G. D. Aurback. 1969. Activation of skeletal adenyl cyclase by parathyroid hormone in vitro. Endocrinology. 84:761-768.

5. Teitelbaum, A. P., R. A. Nissenson, and C. D. Arnaud. 1982. Coupling of the canine renal parathyroid hormone receptor to adenylate cyclase: modulation by guanyl nucleotides and $\mathrm{N}$-ethylmaleimide. Endocrinology. 111:1524-1533.

6. Nissenson, R. A., and C. D. Arnaud. 1979. Properties of the parathyroid hormone receptor-adenylate cyclase system in chicken renal plasma membranes. J. Biol. Chem. 254:1469-1475.

7. Segre, G. V., M. Rosenblatt, B. L. Reiner, J. E. Mahaffey, and J. T. Potts, Jr. 1979. Characterization of parathyroid hormone receptors in canine renal cortical plasma membranes using a radioiodinated sulfur-free hormone analogue. J. Biol. Chem. 254:6980-6986.

8. Fraser, C. L., P. Sarnacki, and A. I. Arieff. 1985. Abnormal sodium transport in synaptosomes from brains of uremic rats. J. Clin. Invest. 75:2014-2023.

9. Gill, D. L., E. F. Grollman, and L. D. Kohn. 1981. Calcium transport mechanisms in membrane vesicles from guinea pig brain synaptosomes. J. Biol. Chem. 256:184-192.

10. Nissenson, R. A., S. R. Abbot, A. P. Teitelbaum, O. H. Clark, and C. D. Arnaud. 1981. Endogenous biologically active human parathyroid hormone: measurement by a guanyl nucleotide-amplified renal adenylate cyclase assay. J. Clin. Endocrinol. \& Metab. 52:840846.

11. Beavo, J. A., O. B. Crofford, J. G. Hardman, E. W. Sutherland, and E. V. Newman. 1970. Effects of xantine derivatives on lipolysis and on adenosine $3^{\prime}, 5^{\prime}$-monophosphate phosphodiesterase activity. Mol. Pharmacol. 6:597-603.

12. Salomon, Y., C. Londos, and M. Rodbell. 1974. A highly sensitive adenylate cyclase assay. Anal. Biochem. 58:541-548.

13. Lowry, O. H., N. J. Rosebrough, A. L. Farr, and R. J. Randall. 1951. Protein measurements with the Folin phenol reagent. J. Biol. Chem. 193:265-275.

14. Seamon, K. B., and J. W. Daly. 1983. Forskolin, cyclic AMP and cellular physiology. Trends Pharmacol. Sci. 120-123.

15. Dascal, N., T. P. Snutch, H. Lubbert, N. Davidson, and H. A. Lester. 1986. Expression and modulation of voltage-gated calcium channels after RNA injection into Xenopus oocytes. Science (Wash. DC). 231:1147-1150.

16. Seamon, K. B., W. Padgett, and J. W. Daly. 1981. Forskolin: unique diterpene activator of adenylate cyclase in membranes and in intact cells. Proc. Natl. Acad. Sci. USA. 78:3363-3367. 
17. Siegl, A. M., J. W. Daly, and J. B. Smith. 1982. Inhibition of aggregation and stimulation of cyclic AMP generation in intact human platelets by the diterpene forskolin. Mol. Pharmacol. 21:680-687.

18. Hruska, K. A., M. Gligorsky, J. Scoble, M. Tsutsumi, S. Westbrook, and D. Moskowitz. 1986. Effects of parathyroid hormone on cytosolic calcium in renal proximal tubular cultures. Am. J. Physiol. 20:F188-F198.

19. Hruska, K. A., D. Moskowitz, P. Esbrit, R. Civitelli, S. Westbrook, and M. Huskey. 1987. Stimulation of inositol trisphosphate and diacylglycerol production in renal tubular cells by parathyroid hormone. J. Clin. Invest. 79:230-239.

20. Katoh, Y., K. L. Klein, R. A. Kaplan, W. G. Sanborn, and K. Kurokawa. 1981. Parathyroid hormone has a positive inotropic action in the rat. Endocrinology. 109:2252-2254.

21. Irvine, R. F., and R. M. Moor. 1986. Micro-injection of inositol 1,3,4,5-tetrakisphosphate activates sea urchin eggs by a mechanism dependent on external calcium. Biochem. J. 240:917-920.
22. Joseph, S. K., K. E. Coll, A. P. Thomas, R. Rubin, and J. R. Williamson. 1985. The role of extracellular calcium in the response of hepatocyte to calcium dependent hormones. J. Biol. Chem. 260:12508-12515.

23. Batty, I. R., R. Nahorski, and R. F. Fine. 1985. Rapid formation of inositol 1,3,4,5-tetrakisphosphate following muscarinic receptor stimulation of rat cerebral cortical slices. Biochem. J. 232:211-215.

24. Heslop, J. P., R. F. Irvine, A. H. Tashjian, and M. J. Berridge. 1985. Inositol tetrakis- and pentakisphosphate in GH4 cells. J. Exp. Biol. 119:395-401.

25. Williamson, J. R., R. H. Cooper, S. K. Joseph, and A. P. Thomas. 1985. Inositol trisphosphate and diacylglycerol as intracellular second messengers in liver. Am. J. Physiol. 17:C203-C216.

26. Prentki, M., T. J. Biden, D. Janjic, R. F. Irvine, M. J. Berridge, and C. B. Wolheim. 1984. Rapid mobilization of calcium from rat insulinoma microsomes by inositol-1,4,5-trisphosphate. Nature (Lond.). 309:562-564. 